\title{
Refinement of international recommendations for cubicles, based on the identification of associations between cubicle characteristics and dairy cow welfare measures
}

\author{
Romain Lardy, ${ }^{1} \odot$ Alice de Boyer des Roches, ${ }^{1 *} \odot$ Jacques Capdeville, ${ }^{2} \odot$ Renaud Bastien, ${ }^{3,4}$ Luc Mounier, ${ }^{1} \dagger$ \\ and Isabelle Veissier ${ }^{1} \dagger$ () \\ ${ }^{1}$ Université Clermont Auvergne, INRAE, VetAgro Sup, UMR Herbivores, F-63122 Saint-Genès-Champanelle, France \\ ${ }^{2}$ Institut de l'Elevage, Antenne de Toulouse - Castanet Tolosan, F-31321 Castanet Tolosan cedex, France \\ ${ }^{3}$ Department of Collective Behaviour, Max Planck Institute for Ornithology, Universitätsstraße 10, Konstanz 78464, Germany \\ ${ }^{4}$ Department of Biology, University of Konstanz, Universitätsstraße 10, Konstanz 78464, Germany
}

\section{ABSTRACT}

Maladjusted cubicles for dairy cattle may cause increased skin alterations, lameness, and dirtiness. The International Commission of Agricultural and Biosystems Engineering has produced several recommendations for cubicle design, but a previous study showed that not all of them seem efficient. Here, we aim to refine and complete these recommendations. We collected data on 76 dairy farms $(2,404$ cows $)$. We modeled the association between combinations of cubicle properties (e.g., type of bedding litter) and dimensions (e.g., cubicle width) relative to cow size, and prevalence of cow skin alterations, lameness, and dirtiness. We used weighted multivariable logistic regression models to predict the presence of skin alteration on the carpus; the neck, shoulder, and back; the flank, side, and udder; and the tarsus or hindquarters. We also evaluated the presence of lameness as well as the dirtiness of the lower hind legs including hocks; the hindquarters, upper hind legs, and flank; the cow rear including tail; and the udder. The risk factors highlighted led us to recommend (1) position cubicles in a way that leaves more than $1 \mathrm{~m}$ of clearance from any obstacle in front of the cubicle; (2) if there is an obstacle on the lateral plane (i.e., where the cubicle partition is) in front ahead of the cow, put the obstacle in front of the fore knees; (3) if there is an obstacle in front of the cow on the median plane (e.g., neck or front rail), the position the obstacle between 1.25 and 1.5 of the cow length from the curb and between 1.0 and 1.25 of its height; (4) use curb height between 0.11 and 0.15 of cow height with no sharp edges on the curb; (5) use round or at least has

Received November 28, 2019

Accepted September 4, 2020.

*Corresponding author: alice.deboyerdesroches@vetagro-sup.fr

$\dagger$ These authors contributed equally to this work. no sharp edges brisket board; (6) use a stone-free soil instead of concrete or use a mattress thicker than $1 \mathrm{~cm}$, with microrelief, and a soft fixing area at the curb, (7) litter with straw (rather than nothing or sawdust) and keep it dry. This risk factor analysis should be followed by experiments in controlled environments to further validate these conclusions and used to update the International Commission of Agricultural and Biosystems Engineering recommendations.

Key words: cubicle housing, comfort, dairy cow, welfare, equipment design

\section{INTRODUCTION}

Skin alteration and lameness in cows are associated with pain (Prunier et al., 2013), and dirtiness is associated with diseases such as environmental mastitis (Schreiner and Ruegg, 2003; Reneau et al., 2005), and thus are likely to result in poor welfare and economic losses. Maladjusted cubicle dimensions are known to be associated with skin alterations, lameness, and reduction in cleanliness in dairy cows kept in loose housing systems (European Food Safety Authority, 2009). Skin alterations occur at areas of the body that are in repeated contact with elements of housing facilities (Weary and Taszkun, 2000). For instance, hock lesions are associated with a high curb or a high neck-rail cubicle (Veissier et al., 2004). Lameness has a multifactorial and complex etiology in which equipment dimensions play a role: lameness is more prevalent when cubicles are too narrow (Sogstad et al., 2005) or too short (Dippel et al., 2009a).

Cubicles are designed to encourage the cow to lie inside but to defecate and urinate in the alley (Fregonesi et al., 2009). Cow dirtiness is thus associated with cubicle features (Veissier et al., 2004) or space allowance (Fregonesi and Leaver, 2002). Further distance from neck rail to cubicle curb correlates to higher the prevalence of dirty udders (Fregonesi et al., 2009). 
The International Commission of Agricultural and Biosystems Engineering (CIGR; Gainesville, FL) produced recommendations for the housing of dairy cows and heifers (CIGR, 1994, 2014). The CIGR proposes cubicle dimensions based on cow body dimensions. Experts formulated these recommendations based on their knowledge of the natural positions and movements of cows when standing up or lying down. A study based on 2,404 dairy cows (de Boyer des Roches et al., 2019) explored the extent to which farms met the CIGR recommendations for cubicles in France and checked the efficiency of complying with the recommendations for animal welfare. Some recommendations were met in most farms (e.g., $75.9 \%$ farms complied with the recommendation for cubicle resting length), whereas some were rarely met (e.g., only $6.0 \%$ of farms complied with the recommendation for a cubicle partition zone for pelvis freedom). Compliance with CIGR recommendations was not always associated with improved welfare (e.g., compliance with the recommendation for cubicle width was associated with fewer skin alterations on tarsus and less lameness, whereas compliance with the recommendation for cubicle length was associated with more skin alterations on the carpus). Therefore, CIGR recommendations for cubicle dimensions need refinement.

The existing literature on the links between cubicle dimensions and prevalence of skin alterations, lameness, and dirtiness often considers dimension in absolute terms (Potterton et al., 2011; Zaffino Heyerhoff et al., 2014) instead of relative to the dimensions of the cows. Furthermore, the literature usually considers only the main types of cubicles found on farms or the average of cubicles dimensions (Westin et al., 2016b), whereas we previously observed that a cow encounters 1.93 different types of cubicles on a farm on average (de Boyer des Roches et al., 2019). In addition, few studies have addressed the combination of factors related to cubicle dimensions (e.g., cubicle length and neck-rail position) and the effects on skin lesions or lameness (Kielland et al., 2009; Potterton et al., 2011; Zaffino Heyerhoff et al., 2014; Westin et al., 2016a).

The aim of our study was to model the association between combinations of cubicle dimensions relative to cow size and other cubicle properties (e.g., type of soil) as well as the prevalence of dairy cow skin alterations, lameness, and dirtiness. This modeling effort served to confirm or disconfirm the benefit of some CIGR recommendations, to refine others, and to propose new ones.

\section{MATERIALS AND METHODS}

The study was carried out in 2010 and 2011. An ethical review was not required for this study in 2010 according to the European Directive 2010/63/EU because our study did not affect the farms' routines: no experimental treatment was applied on animals and they were observed remotely (no invasive measure). Because the data from 2019 were reused for the present study, approval was sought and granted by the VetAgro Sup Ethics Committee for Experiments on Animals (France, agreement number CEEA18) on March 5, 2019. The data used here are part of a larger study that has been reported elsewhere (see de Boyer des Roches et al., 2014, 2019). Only brief descriptions will be given here.

\section{Farms Surveyed}

We visited 76 French commercial dairy farms using cubicle housing. Herd size ranged from 21 to 120 dairy cows, of either Montbéliarde or Holstein breed. Measurements on cows (see below) were performed on a sample of animals chosen at random in the herd. The size of the sample depended on the herd size: if there were 30 or fewer lactating cows in a herd, all of the animals were observed; otherwise 75 to $45 \%$ of cows were randomly chosen, the proportion decreasing with the size of the herd (e.g., 30 cows out of 44, 54 cows out of 120; Welfare Quality, 2009; de Boyer des Roches et al., 2014, 2016). Each farm was visited once, and visits followed the Welfare Quality protocol for dairy cows (Welfare Quality, 2009). All visits were carried out by 5 observers. The observers had been trained in recording skin injuries by a Welfare Quality project partner and trained in recording cow body and farm equipment by the principal investigator. Then, they visited 4 farms and their results were compared against each other and against reference values to ensure accuracy and reproducibility between observers (de Boyer des Roches et al., 2014). Observer agreement with reference values ranged from 74 to $96 \%$ (C. Winckler, University of Natural Resources and Life Sciences, Vienna, Austria, personal communication).

\section{Measurements on Cows}

Skin alteration, dirtiness, and lameness were recorded by direct observation according to the Welfare Quality protocol for dairy cows (Welfare Quality, 2009), and the observer also measured cow's height and length, as described in brief below. When the cows were blocked at the self-locking barrier, the observer stood less than $2 \mathrm{~m}$ from a focal cow, on one side of the body chosen at random, and recorded the number of skin alterations (i.e., hairless patches, lesions, and swellings) on 5 body regions (Figure 1). All types of skin alterations (i.e., hairless patches, lesions, and swellings) were then 
Body dimensions

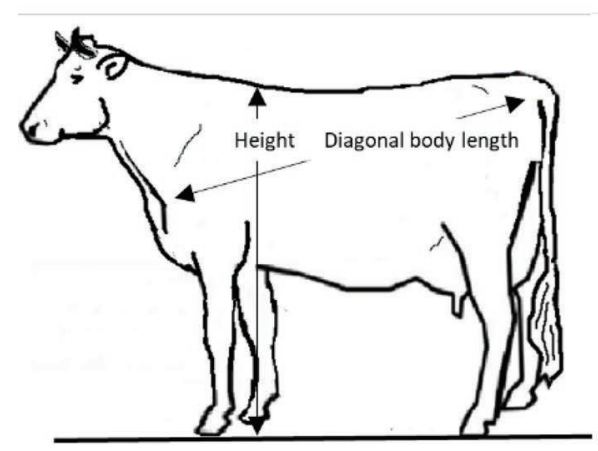

Body regions observed for skin alterations
Body regions observed for dirtiness
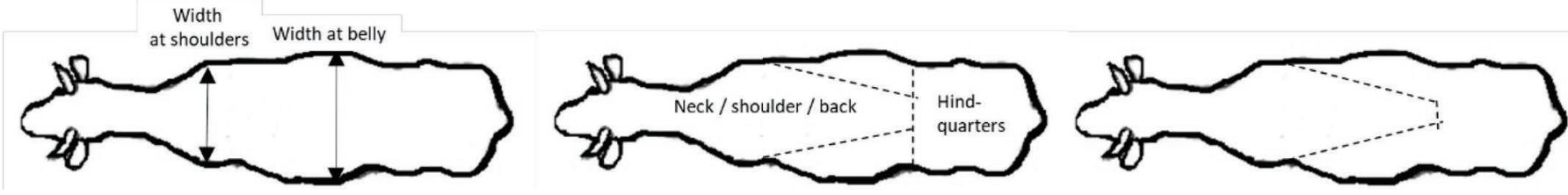

Figure 1. Cow body dimension measurements (height, width, diagonal length) and body areas observed for skin alteration and for dirtiness (Welfare Quality, 2009; borrowed from de Boyer des Roches et al., 2019).

pooled together for each body part (i.e., presence or absence of any skin alteration) for further analyses. The observer also assessed dirtiness on the same side of the focal cow, on the lower hind legs, hindquarters, and udder (Figure 1). Height at withers and diagonal body length of the focal cow were taken using a measuring rod (Figure 1; Table 1; CIGR, 2014). Cow body condition was scored as normal, skinny, or fat (Welfare Quality, 2009). The focal cow was then released from the self-locking barrier to score its locomotion as not lame, moderately lame, or severely lame (Welfare Quality, 2009). Moderate lameness and severe lameness were pooled together for further analysis.

Milk recordings taken from the French milk standards control agency were used to extract each cow's parity, number of DIM, and peak production in the first 3 mo of lactation. Breed (Holstein or Montbéliarde) was also collected. We recorded farm location (highlands or lowlands) and average milk output from the farm $(\mathrm{L} / \mathrm{d}$ per cow).

\section{Dimensions of Cubicles}

The type and dimensions (Figure 2) of the cubicles sometimes varied within farm (some farms had more than 1 type of cubicle). We classified cubicles into 6 types of layout (Figure 3) depending on type and space before obstacles. We recorded the number of cubicles of each type. For each type of cubicle, the observer checked whether the cubicles had the same characteristics, width, and length. Then, the observer randomly selected 1 cubicle per cubicle type for precise measurement. We collected data on the lying area: cubicle surface (flat and concrete or deep-bedded on clay), type of litter (e.g., straw, sawdust), humidity of the litter for the udder or belly area (i.e., the observer took some litter in his hand and then pressed it; if the hand was wet, then the litter was considered wet), number of salient objects in the lying area, type of cubicle floor (flat or deep-bedded), litter and mattress thickness, roughness of the mattress (e.g., macrorelief, microrelief), and hardness of the last $4 \mathrm{~cm}$ of the mattress at the curb. We used a telemeter (AgaTape laser distance meter, AGATEC, Stratford-upon-Avon, UK) to measure the cubicle width (i.e., distance between cubicle partitions), brisket board position (distance from the curb, height, and width), brisket board shape (e.g., rectangle, round) with salient edges or not, neck-rail position (distance from the curb, height), curb height and shape, number of sharp edges on the curb, and the information on the obstacle in front of the cow (type of obstacle, distance from the curb, height; Table 1; Figure 2A). For cubicles with a concrete surface, the curb height corresponded to the difference in height between the walking alley and the cubicle floor (without mattress or litter). For deep-bedded cubicles, the cubicle floor (without bedding) was lower than the curb. However, some flat cubicles on concrete also had a curb higher than the 
Lardy et al.: NEW CUBICLE HOUSING RECOMMENDATIONS FOR DAIRY COWS

2167

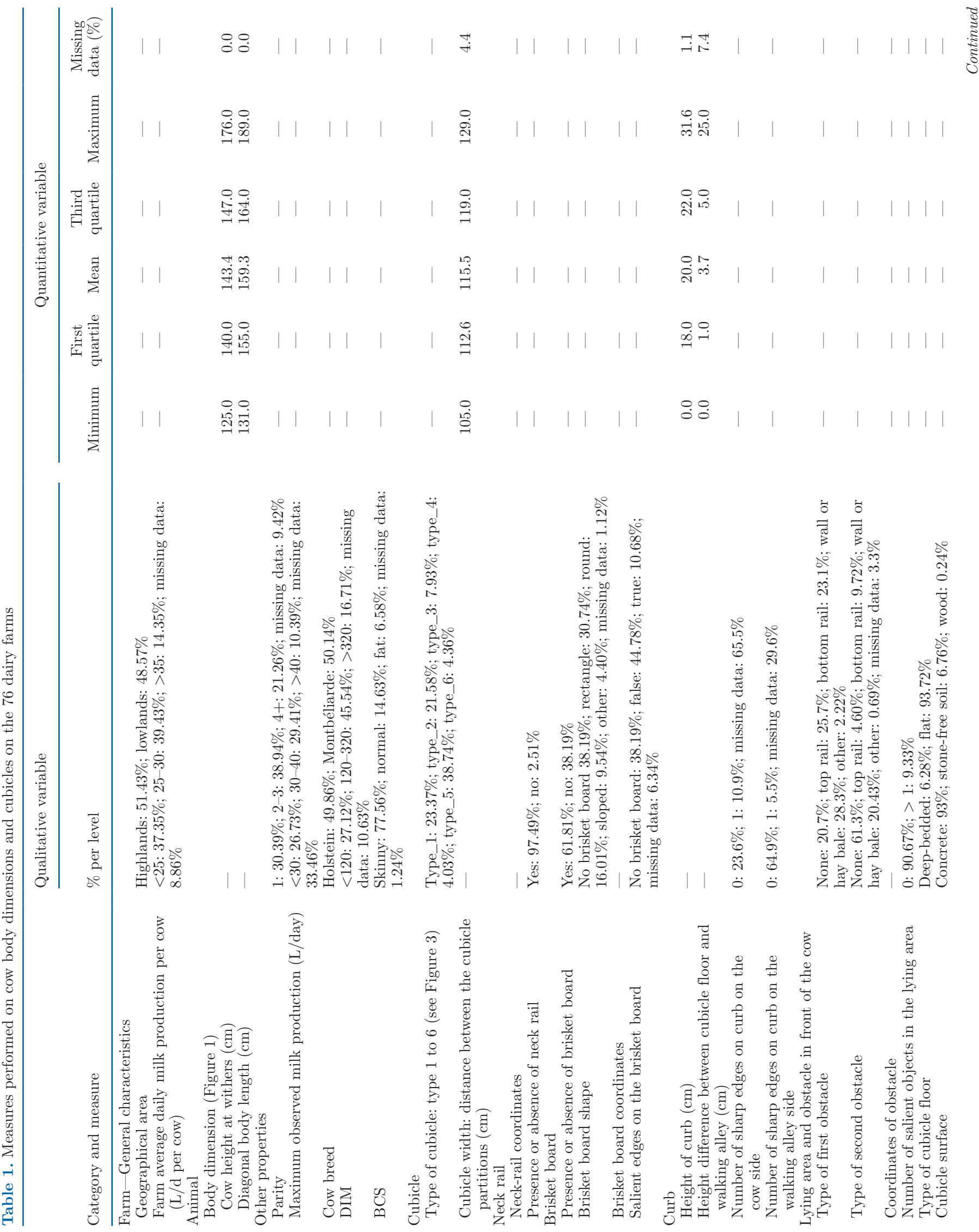




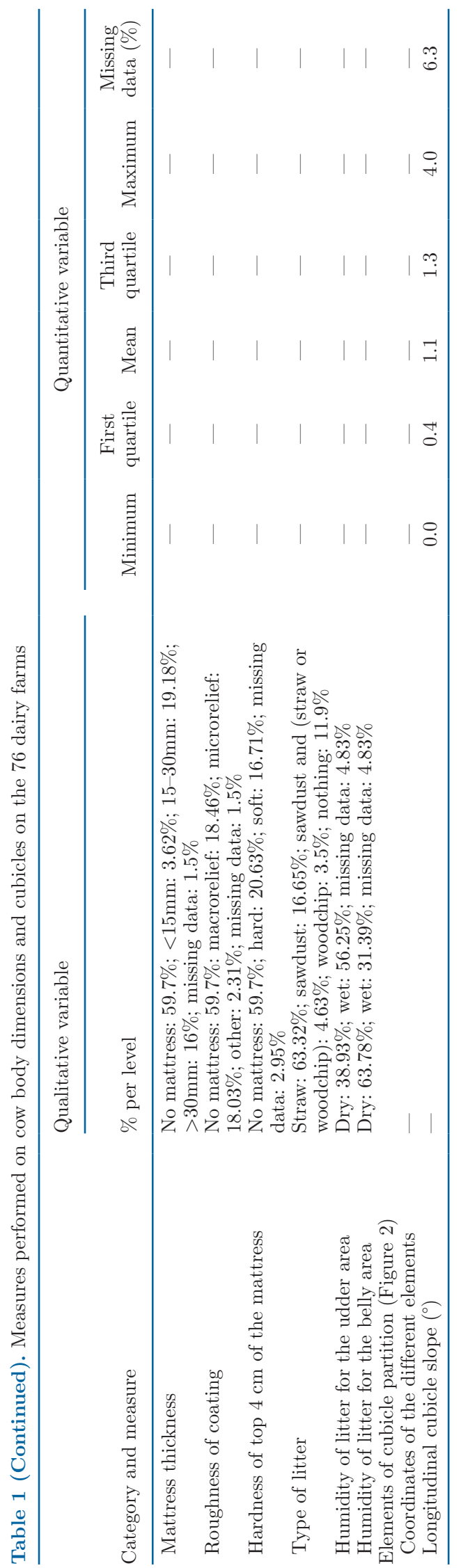

cubicle floor; as shown in Figure 2. We also recorded the position of each cubicle partition element (Table 1; Figure 2B). Curb was the reference for measures in the horizontal plane and the lying floor for measures in the vertical plane. See de Boyer des Roches (2012) for full details on the measurements (pages 245-277) and the recording sheet (pages 340-346) used (in French).

\section{Statistical Analyses}

Analysis included 2,404 cows (on which skin alterations, cleanliness, lameness, height at withers, and body length were recorded; Tables 2 and 3) on 76 farms, of which 30 farms counted 1 cubicle type, 30 farms counted 2 cubicle types, 10 farms counted 3 cubicle types, and 6 farms counted 4 cubicle types. We linked each cow to all cubicles on its farm and obtained 4,649 cow-cubicle dyads in dataset 1 . The cows were in 2 separate pens on only 1 farm. We analyzed the data from the 2 pens as if they came from 2 farms.

Estimation of Cow Width. Due to time constraints, the width of the 2,404 cows could not be measured on the 76 farms (dataset 1). As cow width is potentially a factor for skin alterations, we estimated cow width at shoulders and at belly for the 2,404 cows (dataset 1) using another set of data (dataset 2, available as Supplemental Dataset S1, https://doi.org/10.15454/ CYABLU) provided by J. Capdeville and S. Patouillard (Institut de l'élevage, Castanet Tolosan, France, personal communication). Dataset 2 comprised diagonal body length, height, width at shoulders, and width at belly for 307 Holstein cows (Table 3). Cow dimensions were taken with a measuring rod in dataset 1 and a tape measure in dataset 2 . The tape measure partly biased the measurements of diagonal body length due to the belly shape of the cow. We ran linear regression to predict cow width at shoulders and at belly from cow diagonal body length and height. We checked for normality of the residuals using a quantile-quantile plot, and we checked the homogeneity of the variance graphically (residuals vs. fitted values plot and square root of the residuals vs. fitted values plot). Leave-oneout cross-validation served to estimate the prediction error and give an unbiased estimation of the performance of the models (Refaeilzadeh et al., 2016). Using these equations, we predicted widths at shoulders and at belly for the cows of dataset 1 . We used $\mathrm{R}$ software version 3.4.4 ( $\mathrm{R}$ Core Team, 2018) with the MASS package (Venables and Ripley, 2002) and the car package (Fox and Weisberg, 2011).

Modeling Skin Alterations, Lameness, and Dirtiness from Cubicle Design. We built Boolean data for each cow, accounting for presence versus absence of skin alterations and dirtiness on each body 

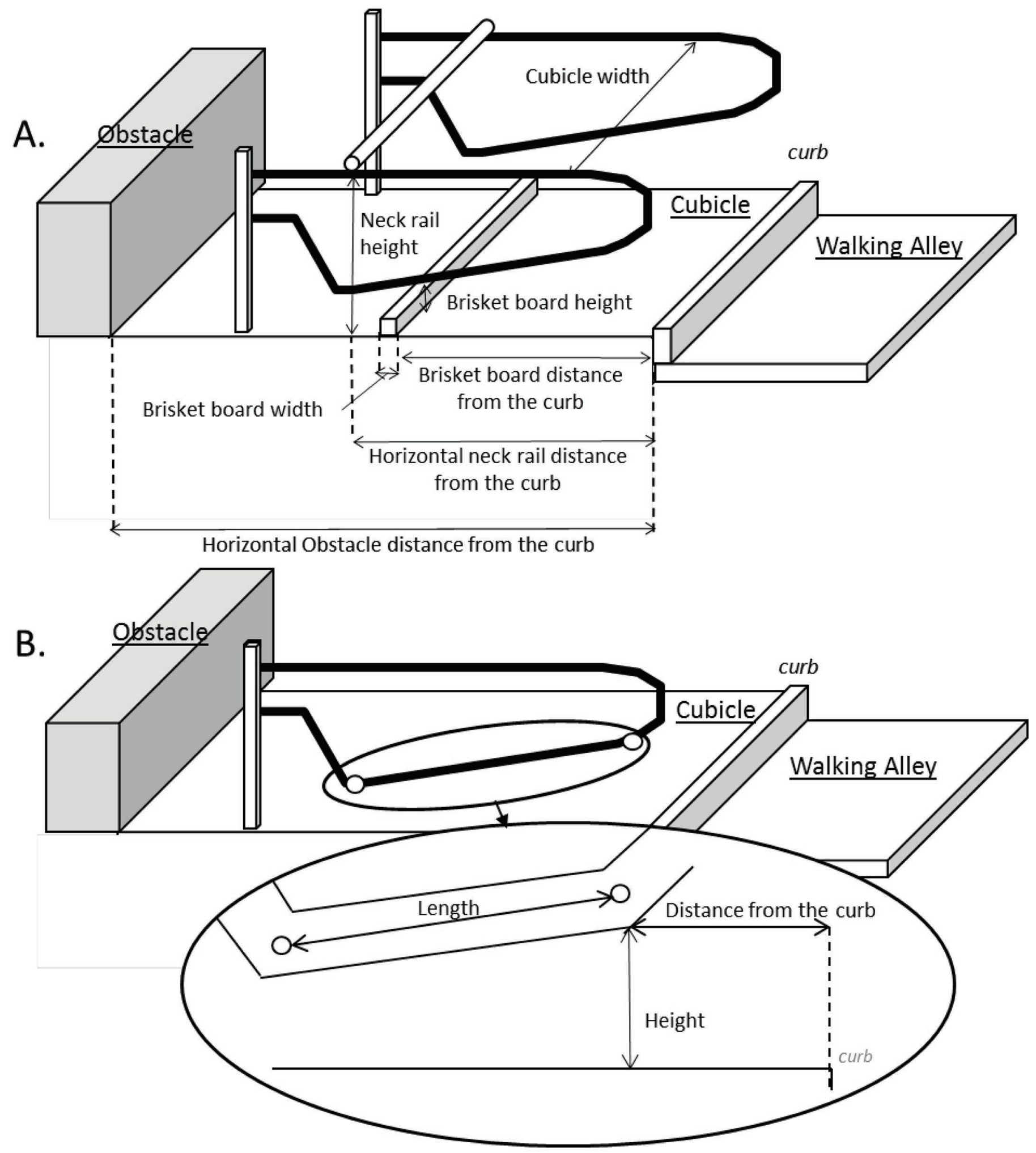

Figure 2. Measures performed on the cubicles (borrowed from de Boyer des Roches et al., 2019). 
Table 2. Prevalence (number and percentage of cows) of skin alterations on carpus; on the neck, shoulder, or back; hindquarters; flank, side, or udder; and tarsus; lameness; and dirtiness of the lower hind legs, hindquarters, and udder in 2,404 cows

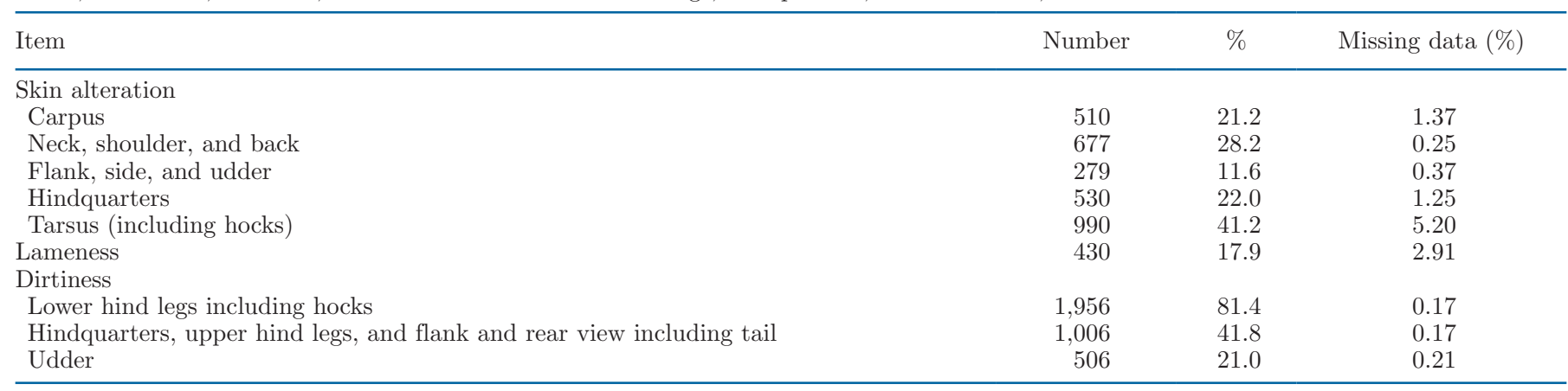

part and presence versus absence of lameness. Based on the recorded cubicle dimensions, we modeled the shape of each cubicle in space (Figure 4 and Supplemental Figure S1, https://doi.org/10.15454/OWPAPV). This information was used to perform a consistency check on the farm data recorded. As cubicle type and dimensions can vary within farm, we assumed that the effect of a given type of cubicle was proportional to its proportion on the farm. For instance, if a type of cubicle represented $80 \%$ of the cubicles on a farm, we assumed that it potentially explained $80 \%$ of skin alterations observed on the cows. We thus employed the proportions of the cubicles on the farm as weights in the following statistical tests, using weighted least square regression instead of a simple least square regression, as in (Lardy et al., 2020).

Using weighted multivariable logistic regression models, we modeled presence or absence of skin alterations on the carpus; on the neck, shoulder, or back; on the flank, side, or udder; on the hindquarters; and on the tarsus, as well as presence or absence of lameness and presence or absence of dirtiness on lower hind legs including hocks; on hindquarters, upper hind legs, or flank; or on the rear including tail and udder. Each model was written as follows: outcome variable $\sim \mathrm{glm}$ (factor $1+$ factor $2+\ldots+$ factor $n$, family $=$ binomial $($ link $=$ logit $)$, weights $=$ cubicle proportions on the farm). The farm was not included as a random factor in the models because each farm is described by the measures of cubicles. Using farm a factor would have led to collinearity with the other factors on cubicles dimensions or design, which were the focus of the study. We built each of the 9 predictive models in 5 steps (Figure 4; Supplemental Figure S2, https://doi.org/10.15454/ OWPAPV).

The first step was to build a variable representing the presence or absence of an obstacle within the space of the cubicle. We considered 2 planes perpendicular to
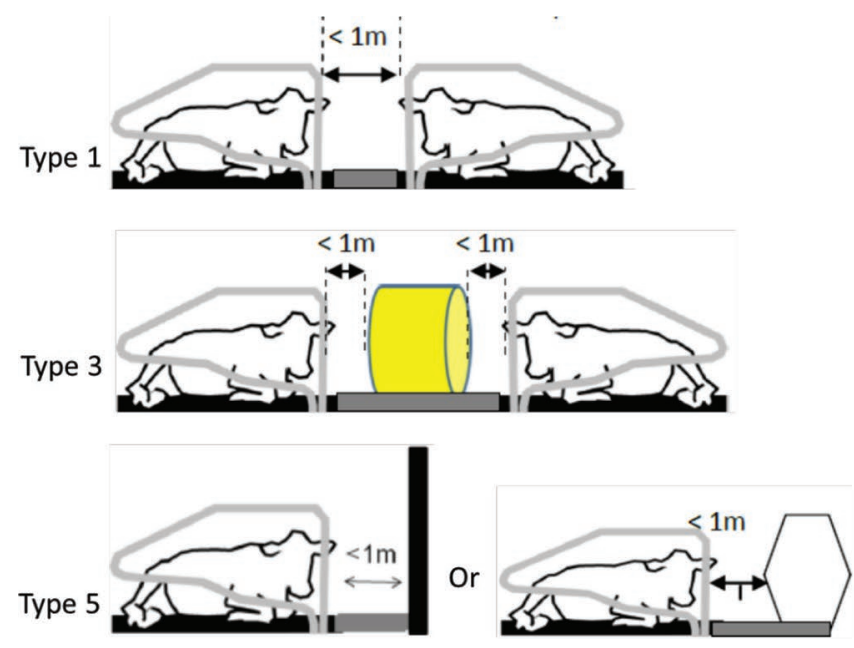
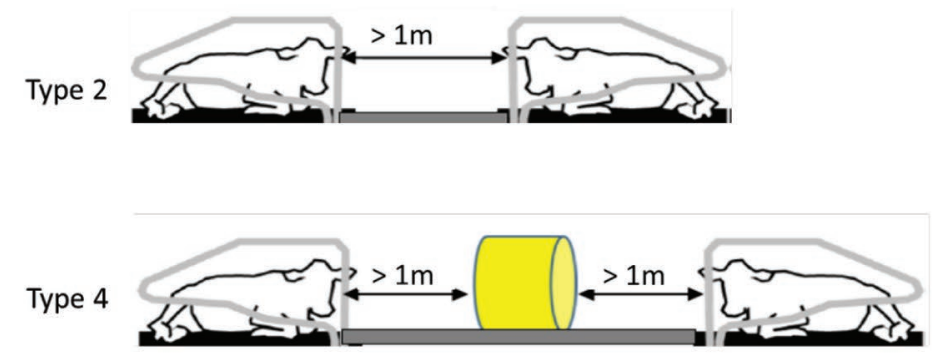

Figure 3. Type of cubicle layout. Type 1 and 2 are head-to-head cubicles, with less or more than $1 \mathrm{~m}$ of free space between the 2 cubicles, respectively. Type 3 and 4 are head-to-head cubicles with straw and hay storage between them. Type 5 and 6 are cubicles with a wall or an obstacle (which can be straw and hay in storage) in front. Types 3 and 5 have less than $1 \mathrm{~m}$ between cubicle and first obstacle, whereas types 4 and 6 have more than $1 \mathrm{~m}$ between cubicle and first obstacle. 
Table 3. Characteristics (height, diagonal length; all measurements in $\mathrm{cm}$ ) of the cows

\begin{tabular}{|c|c|c|c|c|c|c|}
\hline Dataset & Description & Minimum & $\begin{array}{c}\text { First } \\
\text { quartile }\end{array}$ & Mean & $\begin{array}{c}\text { Third } \\
\text { quartile }\end{array}$ & Maximum \\
\hline \multirow[t]{3}{*}{ Dataset 1} & Height at withers & 125.0 & 140.0 & 143.6 & 147.0 & 176.0 \\
\hline & Diagonal body length & 131.0 & 155.0 & 159.6 & 164.0 & 189.0 \\
\hline & Estimated width at last rib & 57.0 & 66.3 & 68.3 & 70.2 & 80.7 \\
\hline \multirow[t]{2}{*}{ Dataset 2 (data to build width equations) } & Height at withers & 130.0 & 139.0 & 142.0 & 145.0 & 154.0 \\
\hline & Diagonal body length & 153.0 & 168.0 & 173.3 & 179.0 & 196.0 \\
\hline
\end{tabular}

the floor: the lateral plane of the cubicle, which represented obstacles on the side of the cow, and the plane through the middle of the cubicle, which represented obstacles in the cubicle (e.g., brisket board and neck rail; Figure 4). We also built a regular mesh on the lateral and median planes, based on the cow length and height (Figure 4). We then calculated the presence or absence of obstacles on each cell of these meshes (Figure 4). We removed cells with prevalence of an obstacle lower than $5 \%$ or higher than $95 \%$. We tested a series of different mesh cell sizes: $50 \% \times 50 \%, 50 \% \times 33 \%$, $25 \% \times 25 \%, 25 \% \times 16.5 \%, 12.5 \% \times 12.5 \%, 10 \% \times 10 \%$ of the cow length and height. However, to simplify this paper, we presented results only for the cell size of $25 \%$ $\times 25 \%$ of the cow length and height.

The second step was to apply univariable logistic regression to analyze the link between skin alterations, lameness, or dirtiness and each of the factors measured (i.e., presence or absence of obstacle, which was built in the previous step, and the 29 factors described in Table 1). The factors with a probability of effect lower than or equal to 0.1 were kept to build a full multivariable model. For quantitative factors, we used the BoxTidwell test to highlight nonlinear effects. If there was a nonlinear effect $(P$-value $<0.1)$, we discretized the factor into 3 classes. We chose the quantile threshold that gave the best Akaike information criterion (AIC) in univariable logistic regression.

The third step was to exclude highly-collinear factors. We estimated correlations between each dyad of factors kept from the previous step. We used the Spearman test for 2 quantitative factors (threshold set at 0.6), Cramer's V intercorrelation coefficient for 2 qualitative factors (threshold set at 0.6), and a linear model for 1 qualitative plus 1 quantitative factor (threshold for the $P$-value of the coefficient linked to the factor $=0.01$ ). To model the diversity of cubicles within each farm, we used cubicle proportions as weights in the tests. Finally, working from highly-correlated factors, we kept those with the best predictive capacity (estimated by the AIC) to construct the full model.
The fourth step was to simplify each full model by bidirectional stepwise elimination according to the AIC. The simplification was stopped when no factor that would decrease the AIC value could be added or removed (Burnham et al., 2011). We also only kept factors with a $P$-value $<0.05$. For qualitative factors, we considered that at least 1 modality (except missing data) needed to be significant with a $P$-value below 0.05 . We chose to ignore results on a factor level representing less than $5 \%$ of the data set (i.e., if a certain class of a factor was observed on less than $5 \%$ of the farm, we considered that there were not enough occurrences to interpret it). For each model, we checked the absence of multicollinearity by calculating the generalized variance-inflation factors. We assumed there was no multicollinearity between the factors of each final model if the generalized variance-inflation factors were less than 3 (Fox and Monette, 1992).

The fifth step was to assess the robustness and efficiency of the model using a leave-one-out crossvalidation (Refaeilzadeh et al., 2016). Cross-validation consisted of removing each cow from the dataset before calculating the coefficients of the model. Then, using the new coefficients, we predicted the probability of skin alteration, lameness, or dirtiness for the missing cow. Two types of cross-validation were performed, either by removing a whole farm or by removing a single cow. We plotted the receiver operating characteristic (ROC) curve, which illustrates the diagnostic ability of a model as its discrimination threshold varies. It corresponded to the true-positive rate against the falsepositive rate at various threshold settings. We used the area under the curve (AUC) index to compare the different models. The AUC index ranges from 0 to 1 , where 1 represents the perfect model, and 0.5 corresponds to a random model (Dohoo et al., 2009).

All calculations were performed with $\mathrm{R}$ software version 3.4.4 (R Core Team, 2018). The speelglm package (Enea, 2017) was used to calculate logistic regressions. The MASS package (Venables and Ripley, 2002), vcd package (Meyer et al., 2017), and Wcorr package (Bai- 


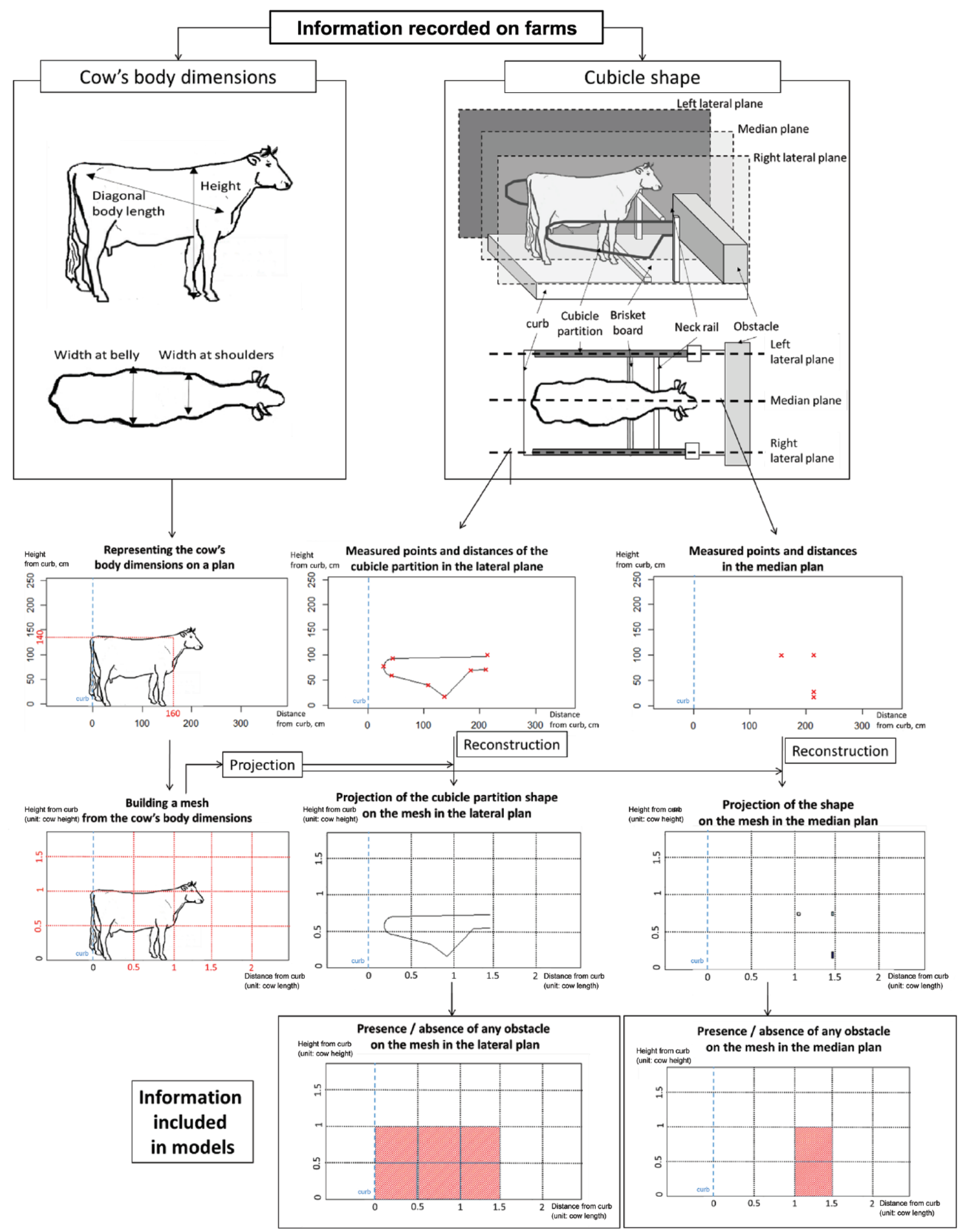

Figure 4. Illustration of the different steps performed to transform raw data on cubicles in relation to cow dimensions into presence or absence of an obstacle on the mesh on the lateral or median planes. 
ley and Emad, 2017) were used to calculate correlations and simplify the models. The ROCR package (Sing et al., 2005) was used to calculate the ROC curves and the AUC indexes. The foreach package (Microsoft Corporation and Weston; 2017a) and the doParallel package (Microsoft Corporation and Weston; 2017b) were used to shorten calculation time for model assessments and to calculate optimal quantile thresholds. Calculations were performed at the Mésocenter Clermont Auvergne supercomputer facilities (Clermont-Ferrand, France).

\section{RESULTS}

The prevalence for skin alterations, lameness, and dirtiness was reported in de Boyer des Roches et al. (2019), Table 2.

\section{Dimensions of Cows}

The cow height range (Table 3 ) in dataset 2 (provided as Supplemental Dataset S1, https://doi.org/10.15454/ CYABLU) used to build the cow width equations was similar to that observed in dataset 1 (mean: 142.0 vs. $143.6 \mathrm{~cm}$ ). Diagonal body length was longer in dataset $2($ mean $=173.3 \mathrm{~cm})$ than in dataset $1($ mean $=159.6$ $\mathrm{cm}$ ). The final equation obtained in dataset 2 to predict width at shoulders was as follows:

$$
\begin{aligned}
& \text { Width at shoulder }(\mathrm{cm})= \\
& 11.06+0.26 \times \text { height }(\mathrm{cm}) .
\end{aligned}
$$

The final equation to predict width at belly was as follows:

$$
\begin{aligned}
& \text { Width at belly }(\mathrm{cm})=-17.03+0.295 \times \text { height }(\mathrm{cm}) \\
& +0.269 \times \text { length }(\mathrm{cm}) .
\end{aligned}
$$

Root mean square error and the root mean square relative error were $3.92 \mathrm{~cm}$ and $8.4 \%$, respectively, for equation 1 , and $6.49 \mathrm{~cm}$ and $9.2 \%$, respectively, for equation 2 . Therefore, we considered equations 1 and 2 as sufficiently reliable and used them to estimate cow widths at shoulder and belly on dataset 1 .

\section{Description of the Cubicles on Farms}

Cubicle characteristics and dimensions are detailed in Table 1. The probability of presence of an obstacle on each cell of the lateral and median cubicle planes is presented in Supplemental Figure S3, https://doi. org/10.15454/OWPAPV. On the cubicle lateral plane
(Supplemental Figure S3A), there was no obstacle higher than the cow height, and maximum prevalence of obstacles found was between [25-75\%] $\times$ [25-75\%] of the cow length and height. On the cubicle median plane (Supplemental Figure S3B), there was no obstacle between the curb and $75 \%$ of cow length, and maximum prevalence of obstacles found was between [100-150\%] $\times[50-100 \%]$ of the cow length and height.

\section{Outcomes of Multivariable Models for Skin Alterations, Lameness, and Dirtiness}

Figure 5 summarizes the effect of the presence of obstacles on skin alterations, lameness, and dirtiness. Significant outcomes $(P<0.05)$ and odds ratios of our multivariable models are summarized in Table 4 and Table 5. All results are detailed in Supplemental Tables S1, S2, and S3 (https://doi.org/10.15454/OWPAPV). The ROC curves obtained through cross-validation are reported in Supplemental Figure S4 (https://doi. org/10.15454/OWPAPV).

\section{Models for Skin Alterations}

The risk for skin alterations on the carpus decreased when the height difference between cubicle floor and walking alley floor was 0.023 to 0.055 high or 0.055 to 0.189 high relative to cow's height, when the mattress was 1 to $6 \mathrm{~cm}$ thick, when the litter under cow's belly was wet, when the material used for cubicle surface was stone-free soil, when the cow was a Montbéliarde, or when there was an obstacle in cubicle lateral plane at [0-25\%] $\times[0-25 \%]$ (i.e., an obstacle present in the median plan between $0 \%$ and $25 \%$ of the cow length, and between $0 \%$ and $25 \%$ of the cow height), [100-125\%] $\times[25-50 \%]$ of the cow length and height, or on the cubicle median plane at $[125-150 \%] \times[0-25 \%]$ of the cow length and height. The risk for skin alterations on the carpus increased when there was an obstacle in the cubicle lateral plane at $[0-25 \%] \times[50-75 \%]$ or $[50-75 \%] \times[50-75 \%]$, or $[100-125 \%] \times[50-75 \%]$ of the cow length and height, and when the litter was sawdust. For this model, the AUC estimated by crossvalidation was 0.78 when removing each cow and 0.74 when removing each farm.

The risk for skin alterations on the neck, shoulder, and back decreased when the cow was a Montbéliarde, when the last $4 \mathrm{~cm}$ of the mattress was soft, and when there was an obstacle in the cubicle median plane at $[75-100 \%] \times[100-125 \%]$, or $[100-125 \%] \times[25-50 \%]$ of the cow length and height. The risk for skin alterations on the neck, shoulder, and back increased when the 
slope of the cubicle was $0.4^{\circ}$ to $1.16^{\circ}$ or between $1.6^{\circ}$ and $4^{\circ}$, when the curb had sharp edges on the cow side [note that the high number $(65 \%)$ of missing data for sharp edges of the curb on the cow side was due to the absence of an edge on the curb], when there was no brisket board or when the brisket board had at least 1 sharp edge, when the cow had a normal BCS, when there was an obstacle in the cubicle lateral plane at $[0-25 \%] \times[0-25 \%]$ or $[0-25 \%] \times[50-75 \%]$, or $[100$ $125 \%] \times[0-25 \%]$ of the cow length and height, and when there was an obstacle in the cubicle median plane at $[75-100 \%] \times[50-75 \%]$. For this model, the AUC estimated by cross-validation was 0.85 when removing each cow and 0.82 when removing each farm.

The risk for skin alterations on the udder decreased when cubicle width was narrower than 1.65 of the cow belly width, and when the curb height was smaller than 0.11 of the cow's height. The risk for skin alterations on the udder increased for older cows (parity $\geq 4$ ), when the height difference between cubicle floor and walking alley floor was 0.023 to 0.055 high or 0.055 to 0.189 high relative to the cow's height, when the litter under the cow's belly was wet, when the litter was sawdust, when there were macrorelief on the surface of the mattress, and when curb height was above 0.15 of cow height. For this model, the AUC estimated by cross-validation was 0.78 when removing each cow, and 0.74 when removing each farm.

The risk for skin alterations on the hindquarters decreased when the cubicle layout was type 1 , when the last $4 \mathrm{~cm}$ of the mattress was soft, when the cow was a Montbéliarde, and when the farm average daily milk production per cow was above $35 \mathrm{~L} / \mathrm{d}$ per cow or below $25 \mathrm{~L} / \mathrm{d}$ per cow. The risk for skin alterations on the hindquarters increased when the height difference between cubicle floor and walking alley floor was 0.023 to 0.055 high relative to the cow's height, when the last $4 \mathrm{~cm}$ of the mattress was not hard as there was no mattress, when the mattress was 1 to $6 \mathrm{~cm}$ thick, when there was no litter, when the curb had sharp edges on

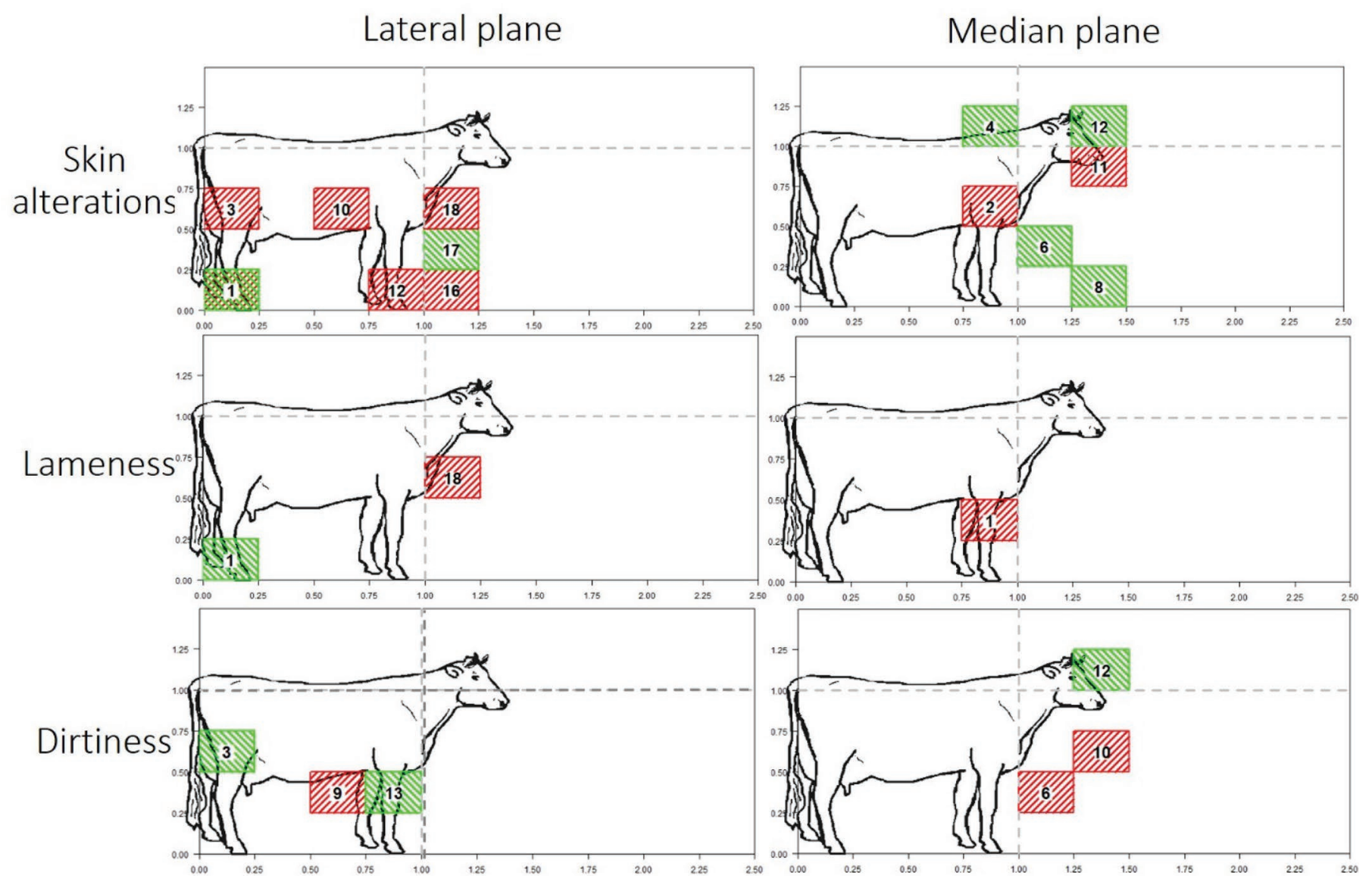

Figure 5. Area of the cubicle (lateral and median plane) that increases (red cells with up bars) or decreases (green cells with down bars) risks for skin alterations, lameness, or dirtiness. Some cells do not exist in the median plane, so cell numbers on the lateral plane may differ from cell numbers on the median plane. The unit for distance from curb is cow relative length (1.0 representing the cow length), and for height from curb is cow relative height (1.0 representing the cow height). 
Lardy et al.: NEW CUBICLE HOUSING RECOMMENDATIONS FOR DAIRY COWS

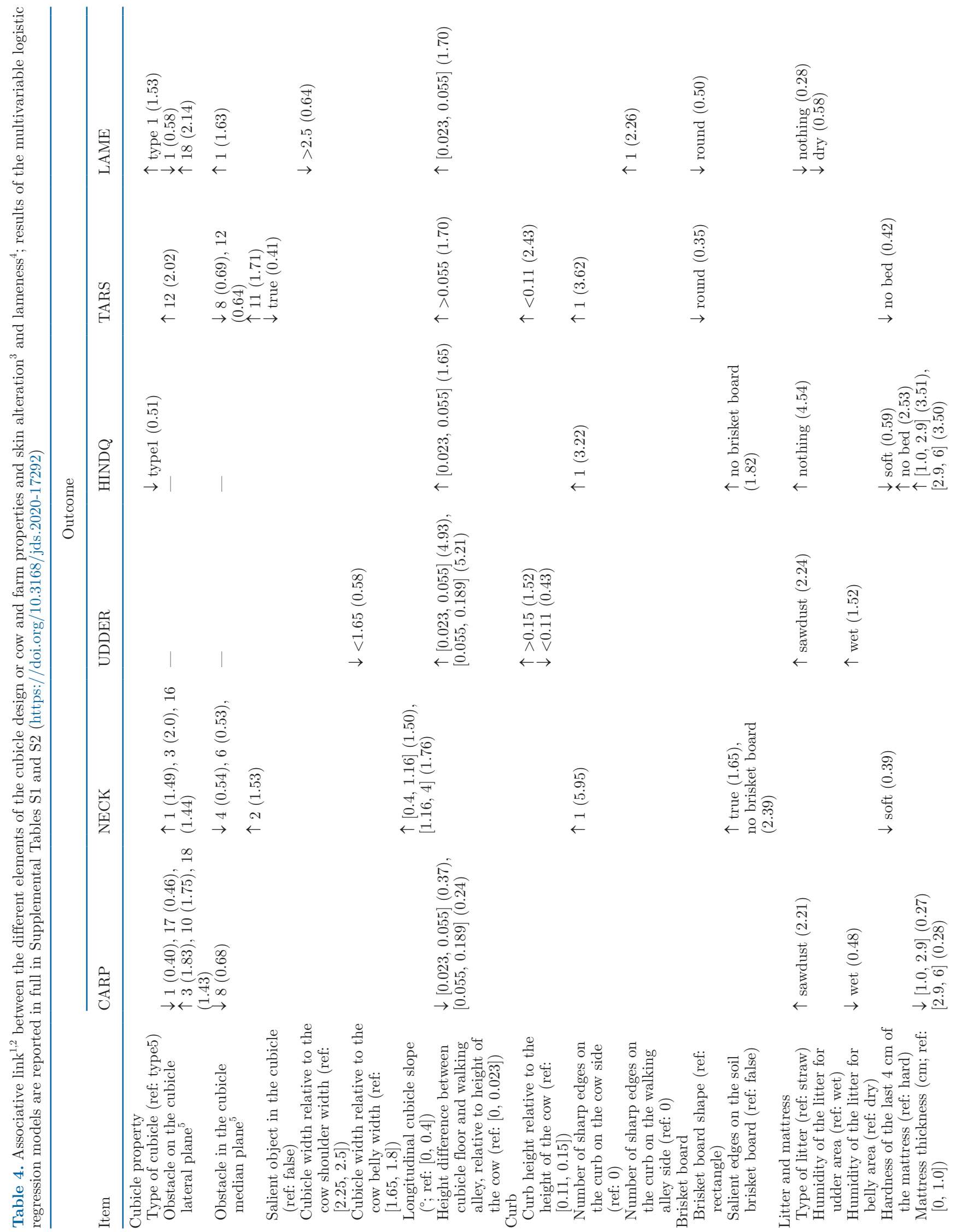


Lardy et al.: NEW CUBICLE HOUSING RECOMMENDATIONS FOR DAIRY COWS

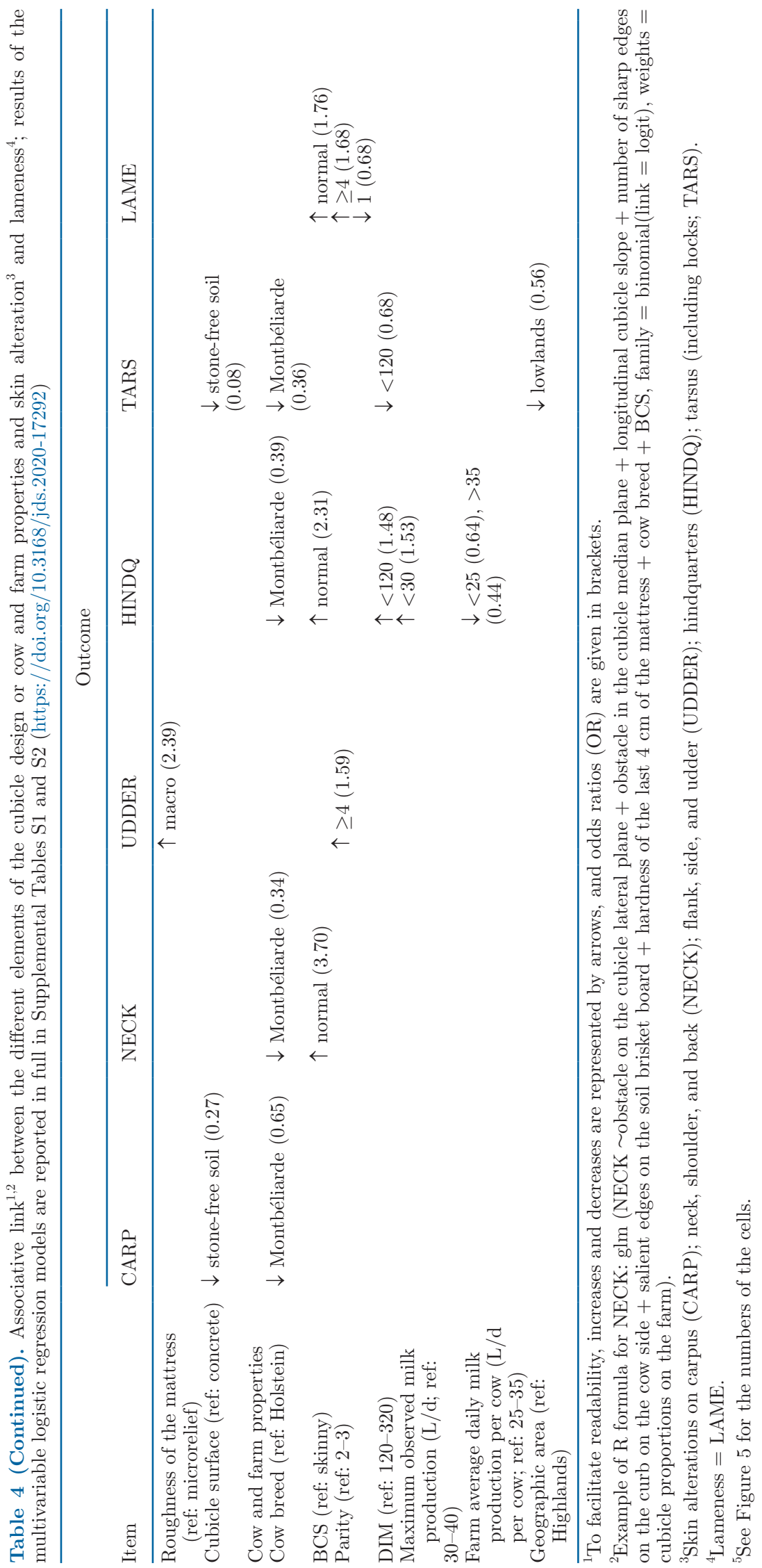


Lardy et al.: NEW CUBICLE HOUSING RECOMMENDATIONS FOR DAIRY COWS

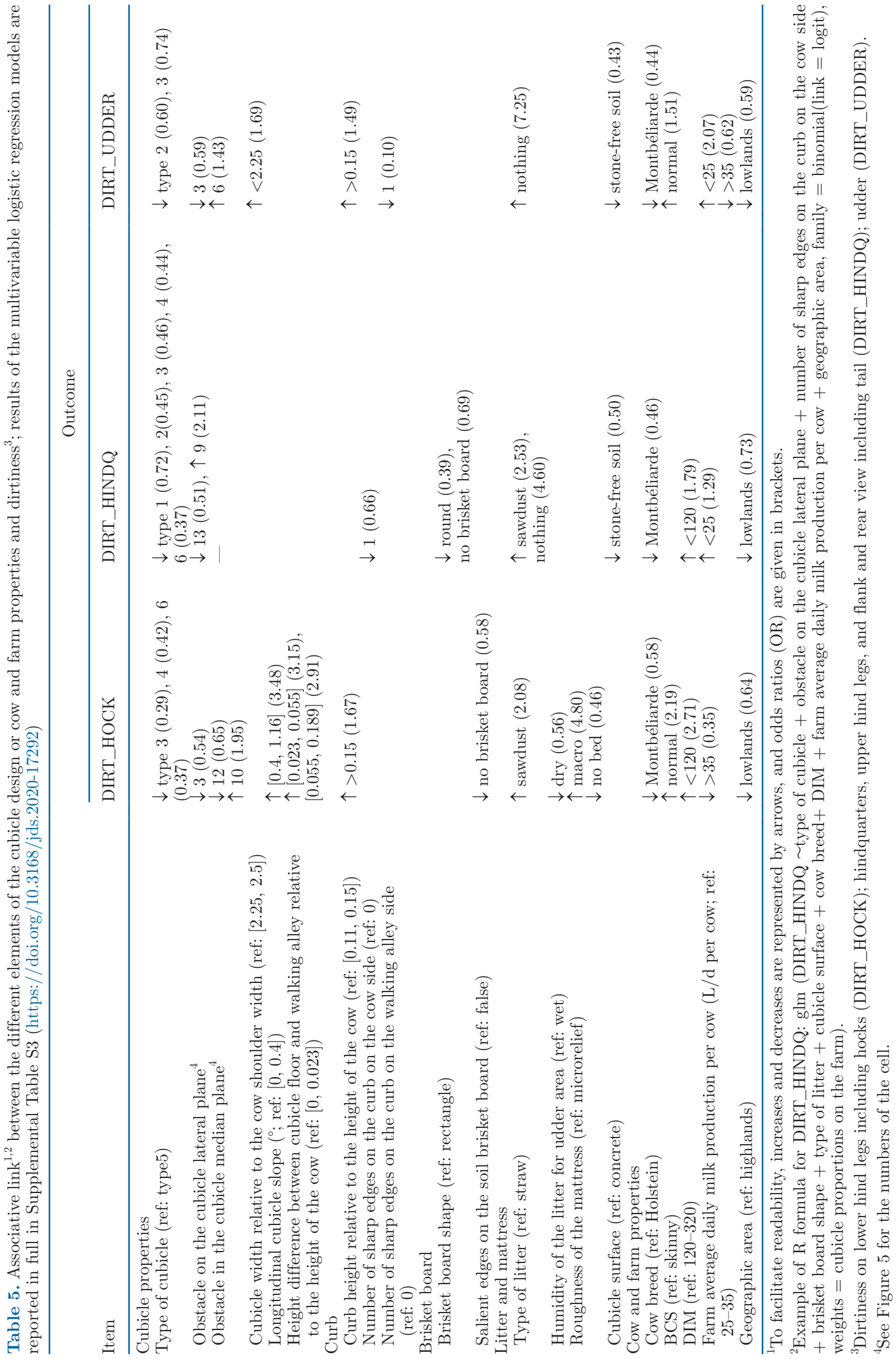


the cow side, when there was no brisket board, when the cow had a normal BCS, when the maximum daily milk production was below $30 \mathrm{~L} / \mathrm{d}$, and when DIM was lower than 120 d. For this model, the AUC estimated by cross-validation was 0.78 when removing each cow and 0.74 when removing each farm.

The risk for skin alterations on the tarsus decreased when there was a salient object in the cubicle, when the material used for cubicle surface was stone-free soil, when the last $4 \mathrm{~cm}$ of the mattress was not hard as there was no mattress, when the brisket board was round, when the farm was located in lowlands, when the cow was a Montbéliarde, when the cow's DIM was lower than $120 \mathrm{~d}$, and when there was an obstacle in the cubicle median plane at [125-150\%] $\times[0-25 \%]$, or [125-150\%] $\times$ [100-125\%] of the cow length and height. The risk for skin alterations on the tarsus increased when the height difference between cubicle floor and walking alley floor was 0.055 to 0.189 high relative to the cow's height, when the curb had sharp edges on the cow side, when curb height was lower than 0.11 of cow height, when there was an obstacle in the cubicle lateral plane at $[75-100 \%] \times[0-25 \%]$ of the cow length and height or in the cubicle median plane at [125-150\%] $\times$ [75-100\%] of the cow length and height. For this model, the AUC estimated by cross-validation was 0.78 when removing each cow and 0.74 when removing each farm.

\section{Models for Lameness}

According to the final models, the risk for lameness decreased for first-parity cows when the brisket board was round, when there was no litter, when the litter under the udder was dry, when cubicle width was wider than 2.5 of cow shoulder width, and when there was an obstacle in the cubicle lateral plane at $[0-25 \%] \times[0-25 \%]$ of the cow length and height. The risk for lameness increased when the cow had a normal BCS, when the cow's parity was above or equal to 4 , when the height difference between cubicle floor and walking alley floor was 0.023 to 0.055 high relative to cow height when cubicle layout was type 1 , when the curb had sharp edges on the walking alley side, when there was an obstacle in the cubicle lateral plane at [100-125\%] $\times$ [50-75\%] of the cow length and height, or in the cubicle median plane at [75-100\%] $\times[25-50 \%]$ of the cow length and height. For this model, the AUC estimated by cross-validation was 0.72 when removing each cow and 0.65 when removing each farm.

\section{Models for Dirtiness}

The risk for dirty lower hind legs decreased when there was no brisket board, when the cubicle layout was type 3,4 , or 6 , when the litter under the cow's udder was dry, when there was no mattress, when there was an obstacle in the cubicle lateral plane at [0-25\%] $\times[50-75 \%]$ of the cow length and height and in the cubicle median plane at $[125-150 \%] \times[100-125 \%]$ of the cow length and height, when the cow was a Montbéliarde, when the farm average daily milk production per cow was above $35 \mathrm{~L} / \mathrm{d}$ per cow, and when the farm was located in lowlands. The risk for dirty lower hind legs increased when the height difference between $\mathrm{cu}^{-}$ bicle floor and walking alley floor was 0.023 to 0.055 high or 0.055 to 0.189 high relative to the cow's height, when the curb height was higher than 0.15 of the cow height, when the slope of the cubicle was $0.4^{\circ}$ to $1.16^{\circ}$, when there was an obstacle in the cubicle median plane at $[125-150 \%] \times[50-75 \%]$ of the cow length and height, when there was a macrorelief on the surface of the mattress, when the litter was sawdust, when the cow's DIM was lower than $120 \mathrm{~d}$, and when the cow had a normal BCS. For this model, the AUC estimated by cross-validation was 0.85 when removing each cow and 0.78 when removing each farm.

The risk for dirty hindquarters, upper hind legs, and flank, and rear view including tail decreased when the curb had sharp edges on the cow side, when cubicle layout was type $1,2,3,4$, or 6 , when the brisket board was round or when there was no brisket board, when the material used for cubicle surface was stone-free soil, when there was an obstacle in the cubicle lateral plane at $[75-100 \%] \times[25-50 \%]$ of cow dimensions, when the farm was located in lowlands, and when the cow was a Montbéliarde. The risk for dirty hindquarters, upper hind legs, and flank, and rear view including tail increased when there was an obstacle in the cubicle lateral plane at $[50-75 \%] \times[25-50 \%]$ of the cow length and height, when there was no litter or sawdust, when the farm average daily milk production per cow was below $25 \mathrm{~L} / \mathrm{d}$ per cow, and when the cow DIM was lower than 120 d. For this model, the AUC estimated by cross-validation was 0.73 when removing each cow and 0.67 when removing each farm.

The risk for dirty udder decreased when cubicle layout was type 2 or 3 , when the curb had sharp edges on the walking alley side, when there was an obstacle in the cubicle lateral plane at [0-25\%] $\times[50-75 \%]$ of the cow length and height, when the material used for cubicle surface was stone-free soil, when the cow was a Montbéliarde, when the farm average daily milk production per cow was above $35 \mathrm{~L} / \mathrm{d}$ per cow, and when the farm was located in lowlands. The risk for dirty udder increased when curb height was higher than 0.15 of cow height, when the cubicle width was narrower than 2.25 of cow width at shoulder, when there was an obstacle in the cubicle median plane at $[100-125 \%] \times$ 
[25-50\%] of the cow length and height, when there was no litter, when the cow had a normal BCS, and when the farm average daily milk production per cow was below than $25 \mathrm{~L} / \mathrm{d}$ per cow. For this model, the AUC estimated by cross-validation was 0.78 when removing each cow, and 0.71 when removing each farm.

\section{DISCUSSION}

This study highlighted risk factors for dairy cow skin alterations, lameness, and dirtiness linked to cubicle design (i.e., cubicle width, type of litter, mattress roughness). The findings presented here are based on associative (not causal) links between cubicles characteristics and cow welfare. As in epidemiological surveys, risk factors can be considered as causal effects if they happen before that effect and if the causal effects are biologically plausible (Toma et al., 2018). The effects of changes in cubicles design on skin alterations is rapid. For instance, adding a brisket board in cubicles decreases the number of external alterations within a month (Veissier et al., 2004). Because the cows had been accommodated in their barn for several months, we consider that in our study the factors depending on cubicles and measured in this study are those that could have caused the alterations, lameness, and dirtiness observed on cows. Our results will thus be discussed according to whether they confirm or allow to refine earlier recommendations from CIGR (2014), and if not, whether one can identify a potential pathway by which a given factor may affect cows.

\section{Confirmation of CIGR Recommendations}

The CIGR recommends cubicles to be wider than 0.83 of the cow's height. In our study, cubicles wider than 2.5 of cow shoulder width were associated with a decreased risk of lameness. The cows were on average $48.4 \mathrm{~cm}$ wide at shoulders and $144 \mathrm{~cm}$ high. For an average cow, the threshold that we identified corresponded to $121.0 \mathrm{~cm}(2.5 \times 48.4 \mathrm{~cm})$, while CIGR would recommend $119.5 \mathrm{~cm}(144 \times 0.83 \mathrm{~cm})$. The 2 thresholds are very close. Our results thus confirm the CIGR recommendation for cubicle width and allow us to express this recommendation relative to the cow width at shoulders.

The CIGR recommends the curb between the alley and the cubicle floor to be at least $15 \mathrm{~cm}$ high to discourage cows from lying partly in alleys, but not higher than $20 \mathrm{~cm}$ to avoid too much weight on the hind legs when cows enter or leave cubicles or stand partly in cubicles. We observed more cow with skin alterations on carpus when the curb was lower than 0.11 of the cow height (15 cm for a cow $144 \mathrm{~cm}$ high ). We also observed more cows with skin alterations on the udder and the hindquarters, as well as more lame or dirty cows when the curb was high, especially when it was higher than 0.15 of cow height $(21.6 \mathrm{~cm}$ for a cow 144 $\mathrm{cm}$ high), which is close to the CIGR recommendation. It is possible that a too high curb leads to cows lying partly outside cubicles, which could result in skin alterations due to body contacts with the edge of the curb, and to dirtiness due to a cow's body touching the manure in the alley. Indeed, the presence of sharp edges on the curb was associated with more lame cows, or more cows with skin alterations, especially on tarsus, hindquarters, and neck, shoulder, and back. In addition to recommending the curb dimensions be between 15 and 20 to $22 \mathrm{~cm}$, or more likely between 0.11 and 0.15 times the cow height, we recommend the curb to have a smooth edge to avoid injuring cows.

In our study, a concrete cubicle base (compared with a stone-free soil) and a mattress thinner than $1 \mathrm{~cm}$ were associated with more cows with skin alteration on the carpus. Dirtier hindquarters and udders were also noticed in such conditions as well as when the litter was not dry, when sawdust was used as a bedding material, or when there was no litter at all. Previous data on bedding material are contradictory. On one hand, Nielsen et al. (2011) found no significant effect of cubicle surface on dirtiness, as it was not kept in their final model, but their data set did not contain farms with sawdust bedding. On the other hand, Potterton et al. (2011) found that sawdust increased the risk of hock skin alterations compared with straw. Regarding humidity, cows spend more time lying on dry litter (Fregonesi et al., 2007), and consequently less time in the corridor, and thus have less dirty hind legs. Wet litter on the belly area decreased the risk for skin alteration on the carpus, but increased the risks for lameness and skin alteration on the udder. Udder skin exposed to humidity is more vulnerable to skin alteration (European Food Safety Authority, 2012). Therefore, our results bear support to CIGR recommendations that the cubicle base must provide a comfortable, clean, and dry surface by using nonconcrete floors or appropriate bedding with mattresses and litter but not sawdust. However, in our study, mattresses thicker than $1 \mathrm{~cm}$ were associated with more cows with skin alterations on the hindquarters. More detailed studies are necessary to identify the optimum thickness of mattresses.

\section{Refinement of CIGR Recommendations}

The CIGR (2014) recommends using obstacles to help cows position themselves in the center of cubicles when they are lying down to optimize cows' lying surfaces within the barn and to keep cows clean. More 
precisely, obstacles on the lateral plane of cubicles encourage cows to lie down parallel to cubicle barriers, while obstacles in the median plane (especially a brisket board and a neck rail) prevent cows from lying too forward. The CIGR also recommends that a curb separates the cubicle from the walking alley, which is often covered by manure, and that the cubicle floor is covered by some litter (see above). Our work helps to refine these recommendations.

While helping the positioning of cows, obstacles in cubicles can also cause alterations. Indeed, in our study, obstacles in the lateral plane of cubicles were associated with less or more skin alterations, lameness, or dirtiness, depending on their location. First, lateral obstacles in front of the fore knees (cell 17, Figure 5) were associated with less cows with skin alteration on the carpus, and obstacles above the fore knee (cell 13) were associated with cleaner hindquarters. Therefore, we recommend positioning lateral obstacles at these locations rather than at others. Second, lateral obstacles next to the hind feet (cell 1) were associated with less cows with skin alterations on the carpus or lameness, but with more cows with skin alterations on the neck, shoulder, and back. Such obstacles may encourage cows to put their tarsus below the body instead of to the side, which could make rising up easier by putting less weight on the fore knees, and thus decrease risks for skin alterations on the carpus. In turn, cows that can lie down or rise up easily are less prone to lameness (Dippel et al., 2009a,b). However, the location of an obstacle on cell 1 may also rub the back of the cow while she is lying, and consequently increase the risk for skin alteration on the neck, shoulder, and back. Additional observations of precise lying positions and standing up and lying down movements are needed to confirm this hypothesis and provide a clear recommendation. Third, lateral obstacles just above the cow hocks (cell 3) were associated with more clean cows but with more cows with skin alterations on carpus and neck, shoulders, and back. We assume that skin alterations are more severe problems for cow welfare than dirtiness because (1) skin alterations can be a source of pain and (2) simple changes to practices (i.e., more frequent litter addition) can increase cleanliness. Therefore, we propose that the unobstructed zone for pelvis freedom, defined as zone iii in CIGR (2014), should include this cell. We also observed that lateral obstacles at specific locations near the cows' front body parts were associated with more risks of skin alterations or lameness [obstacles next to the chest (cell 10), the forefeet (cell 12) or slightly more in front (cell 16), or on the area in front of the shoulders (cell 18)] or dirtiness [obstacles below the chest (cell 9) and near the fore feet (cell 12)]. Obstacles on these locations should be avoided. Our re- sults showed that obstacles at many locations constrain cows. We suggest using flexible partitions between cubicles (e.g., with loose tubes or panels, instead of fixed partitions, to encourage cows to lie in a correct position in the cubicle while reducing the risks for injuries), as such devices were already found to be preferred by cows (Ruud and Bøe, 2011).

Similarly, obstacles in the median plan of cubicles can be beneficial or detrimental depending on their locations. In our study, obstacles in front of the fore knees (cells 6 and 8) or just above the neck (cell 4) were associated with less cows with skin alterations on carpus tarsus, or the neck, shoulder, and back. These obstacles generally correspond to the brisket board and the neck rail. Our results confirmed the beneficial effects of these devices when located adequately (e.g., Potterton et al., 2011). By contrast, obstacles at the level of the fore knees (cell 1) were associated with more lame cows and those in front of the front knees or shoulders (cells 6 and 10) were associated with more dirty cows. Such obstacles corresponded to a brisket board positioned either too high and not far enough from the curb or too far forward. A brisket board not far enough from the curb probably makes lying in the cubicle uneasy due to the reduced cubicle length available, which in turn can promote lameness (Dippel et al., 2009a,b). A brisket board too far forward may fail to help the cow to position in the middle of the cubicle (Tucker et al., 2005). In addition, in our study, salient edges on the brisket board were associated with more cows with skin alterations, whereas round brisket boards were associated with less cows with skin alterations and less lame or dirty cows. Again, obstacles below the cow chin (cell 11) were associated with more skin alteration on the tarsus. A neck rail located here prevents the cow from standing with her body fully in the cubicle, resulting in a lying position with the tarsus against the curb, and thus increasing the risk for skin alteration on this area. If there has to be an obstacle in front of the cubicle, it should be positioned higher than the cow height, as this did not seem to induce skin alteration (cell 12). According to our results, the brisket board should not have sharp edges and should be located just in front of the cow knees, and the neck rail should be located above its shoulders.

On the farms we surveyed, there was often less than $1 \mathrm{~m}$ free in front of cubicles, and such a short free space led to increased cow dirtiness and lameness, especially in case of head-to-head cubicles. Cows need about onethird of their length, corresponding to $53 \mathrm{~cm}$ for an average $160 \mathrm{~cm}$ long cow (i.e., $60-100 \mathrm{~cm}$; Ceballos et al., 2004), for launching their heads when they lie down or get up. In case of head-to-head cubicles, a cow may also be less motivated to lie down when another cow, 
especially a dominant one, lies in the opposite cubicle (Galindo and Broom, 2000). As reported above, such difficulties in lying can increase the risks for lameness (Dippel et al., 2009a,b). Therefore, we highly recommend positioning cubicles to leave more than $1 \mathrm{~m}$ without obstacles in front of the cow (cubicles referred as type 2, 4, and 6 in the present paper). Observation of lying behavior in relation to cubicle layout and other influential factors such as cow social rank (Galindo and Broom, 2000) or density (Lobeck-Luchterhand et al., 2015) would provide information on how exactly these affect cow movements and lameness.

The CIGR recommends use of mattresses on cubicle floors, but the recommendation is not detailed. In more than half of the farms that we surveyed, we observed that the first part $(4 \mathrm{~cm})$ of the mattress, where it is fixed to the curb, was hard; this was associated with more cows with skin alterations. We also noticed that the mattresses were sometimes rough (i.e., macrorelief), which was associated with more skin alterations on the udder. A similar result was found by Gieseke et al. (2020) and Potterton et al. (2011); the latter reported that older mats and mattresses may become less abrasive as they age, thus decreasing the risks of lesions. Therefore, we recommend mattresses to be soft all along the length of the cubicles, and for their surfaces to be smooth (i.e., with microrelief).

\section{Risk Factors Not Identified by CIGR}

Some unexpected links were noticed during our survey. Cubicles narrower than 2.25 relative to cow shoulder width were associated with more cows with a dirty udder, but fewer cows with skin alterations on the udder. It may be that in too narrow cubicles, cows lie down out of cubicles, resulting in dirty udders but less skin alterations due to less collisions with cubicle partitions. Also, the presence of a salient object in the cubicle decreased the risk of skin alteration on the tarsus. In such cubicles, as in narrow ones, cows may lie with the tarsus out of the cubicle. Nevertheless, it would be counterproductive to conclude that cows should be in narrow cubicles or that salient objects should be present. Indeed, having narrow cubicles implies less freedom of movement, and could increase risks for lameness (Sogstad et al., 2005) or injuries (Veissier et al., 2004). Again, one cannot expect salient objects to be directly positive for cow welfare because their contact induces discomfort and could induce skin alterations. Such factors require detailed observations of cows' behaviors when resting before their effects are clearly understood.

In our study, compared with flat cubicles, slightly inclined cubicles (between 0.4 and $1.16^{\circ}$ ) increased the risk for hock dirtiness, but no significant effect of more inclined cubicle was observed. The CIGR recommends a slope of the cubicle floor from $2 \%$ to $4 \%\left(1.15^{\circ}\right.$ and $2.29^{\circ}$ ) to provide a good drainage of the cubicle. Haskell et al. (2006) found that an inclined stall increased hockswelling risks, but they did not detail the degree of inclination. Above such a slope, there seems to be a risk of high SCC (Veissier et al., 2004). The effect of cubicle slope on the cleanliness and injuries of cows requires specific investigations before a firm recommendation can be produced.

On our sample of farms, the risks for dirtiness and skin alterations increased in cows from highland farms with a low milk production. We cannot exclude that these effects are due to third factors such as management or housing (out of cubicle design), which had an effect on cows. In addition, cows in the first half of the lactation, old cows, or Holstein cows (compared with Montbéliarde cows) were more at risk. The relations reported in this paragraph were not the focus of the present paper and will not be discussed further.

\section{Performances of the Models and Limits of the Study}

This study was performed on a data set of 2,404 cows from 76 dairy farms that allowed us to construct models combining multiple factors. These models showed good performances (AUC from 0.85 to 0.72 , obtained by cross-validation when removing each cow), suggesting that cubicle characteristics determine a large part of a cow's skin alterations, dirtiness, and lameness. By considering only elements that were present in more than $5 \%$ of the farms, we avoided overinterpretations. Montbéliarde cow width was estimated by an equation obtained from Hosltein cows; consequently, there may have been a bias in the assessment of cubicle width relative to cow width for Montbéliarde cows. The threshold that we found (2.5 of cow shoulder width) and that of CIGR (1.65 of cow belly width) yield similar values for cubicle width (for an average $144 \mathrm{~cm}$ high, our threshold is $121.0 \mathrm{~cm}$ and the threshold for CIGR is $119.5 \mathrm{~cm}$ ); therefore, we expect the bias on width estimation not to affect the results obtained on Montbéliarde cows. Other factors not addressed here may have an effect on cows' dirtiness and skin alterations. For instance, walking alley floor surface is known to affect the prevalence of lameness, and top-rail height of self-locking barriers is known to affect the prevalence of skin alteration on the neck, shoulder, and back (for a review, see European Food Safety Authority, 2009). Such factors are likely to explain the remaining variability between cows. By considering factors expressed relative to cow dimensions, we were able to propose 
recommendations with a generic value (summarized in the conclusion below). These recommendations could be confirmed by experimentally manipulating the design and the dimensions of cubicles, all other things being equal, and precisely observing the behavior of cows when lying down and standing up (especially collisions against cubicles) and, at the same time, their skin alterations and dirtiness (detailing each body region). Such experiments are expensive and time consuming. The present study can help focus future experiments on main risk factors, with variations around the optima that we described here.

\section{CONCLUSIONS}

We modeled the association between combinations of cubicle dimensions relative to cow size and other $\mathrm{cu}-$ bicle properties, and the prevalence of skin alterations, lameness, and dirtiness in dairy cows. This modeling effort served to confirm or disconfirm the benefit of some CIGR recommendations, to refine these recommendations, or to propose new ones. We confirmed the CIGR recommendation on cubicle width (cubicle width $\geq 0.83$ of cow height) and proposed to add the recommendation of cubicle width $\geq 2.5$ of cow shoulder width. We also confirmed the recommendation on curb height to range from 0.11 to 0.15 of cow height (i.e., about 16-22 cm for an average cow) and suggested to add the recommendation of no sharp curb edges. In addition, we confirmed that the cubicle base must provide a comfortable, clean, and dry surface by using nonconcrete floors or appropriate bedding. On concrete, we recommend adding a mattress thicker than $1 \mathrm{~cm}$, with microrelief, and soft over the last $4 \mathrm{~cm}$ (fixing area). Regarding the litter, we recommend using straw litter rather than nothing or sawdust, and to keep the litter dry. We propose to refine the CIGR's recommendation of using obstacles to help cows position themselves in the center of cubicles when they are lying down, to optimize cows lying surface within the barn, and to keep cows clean. In particular, our results suggest that obstacles in the lateral plane should be positioned in a way to avoid contacts. More specifically, if there must be an obstacle in front of the cow, it should be positioned in front of the fore knees, and the height of the zone for pelvis freedom should be at least 0.75 of the cow height (instead of $0.45-0.60$ of cow height in CIGR), about $108 \mathrm{~cm}$ for an average cow measuring $144 \mathrm{~cm}$. In case of an obstacle in front of the cow in the median plane, it should be positioned higher than the cow height and at 0.75 to 1.0 of the cow length from the curb. As new recommendations, we propose to have a round brisket board, or at least a brisket board without sharp edges, and to position cubicles in such a way to leave more than $1 \mathrm{~m}$ of unobstructed space in front of the cow (cubicles from type 2, 4, and 6) or if not possible, with head-to-head cubicles that share space with straw and hay storage between them.

\section{ACKNOWLEDGMENTS}

This work received financial support from Danone Research (Paris, France), from the pole Enseignement Sciences Technologiques et d'Innovation dans les domaines du Vivant et de l'Environnement-ESTIVE (Clermond-Ferrand, France), and from the French government [Initiative D'EXcellence-Initiative Science-Innovation-Territoires-Économie (IDEXISITE) initiative 16-IDEX-0001, Clermont-Auvergne Project (CAP) 20-25, Clermont-Ferrand, France]. We thank the Groupements de Défense Sanitaire [GDS 69 (La Tour de Salvagny, France), GDS 42 (Saint Priest en Jarez, France), GDS 43 (Le Puy en Velay, France), GDS 63 (Aubière, France), GDS 15 (Aurillac, France), GDS 38 (Rives, France), GDS 73-74 (Saint Baldoph, France), GDS 01 (Ceyzériat, France), GDS 35 (Rennes, France), GDS 56 (Vannes, France), GDS 22 (Ploufragan, France), GDS 44 (Nantes, France), GDS 53 (Laval, France), GDS 49 (Trélazé, France), GDS 85 (La Roche sur Yon, France)] for providing lists of eligible farms, and all the farmers who voluntarily cooperated in this survey. We are also particularly grateful to Eric Delval and Christophe Mallet (INRAE, Clermont-Ferrand, France), Maud Coignard of Nantes-Atlantic National College of Veterinary Medicine, Food Science and Engineering (ONIRIS, Nantes, France), and Remi Debauchez of the Institut supérieur d'agriculture Rhône-Alpes (ISARA, Lyon, France) for their help with data collection; JeanYves Audiart (ONIRIS), Didier Billon (ONIRIS) and Eric Delval (INRAE) for their help with data entry; and Jos Noordhuizen, Raphaël Guatteo (ONIRIS), Nathalie Bareille (ONIRIS), and Claire Agabriel (VetAgro Sup, Clermont-Ferrand, France) for their valuable advice on survey design. The authors thank Metaform Langues (Clermond-Ferrand, France) for copy-editing the paper. The authors have not stated any conflicts of interest.

\section{REFERENCES}

Bailey, A., and P. Emad. 2017. WCorr: Weighted Correlations R Package. Accessed Nov. 3, 2020. https://cran.r-project.org/web/ packages/wCorr/index.html.

Burnham, K. P., D. R. Anderson, and K. P. Huyvaert. 2011. AIC model selection and multimodel inference in behavioral ecology: Some background, observations, and comparisons. Behav. Ecol. Sociobiol. 65:23-35. https://doi.org/10.1007/s00265-010-1029-6.

Ceballos, A., D. Sanderson, J. Rushen, and D. M. Weary. 2004. Improving stall design: Use of $3-\mathrm{D}$ kinematics to measure space use 
by dairy cows when lying down. J. Dairy Sci. 87:2042-2050. https: //doi.org/10.3168/jds.S0022-0302(04)70022-3.

CIGR. 1994. The design of dairy cows housing-Report of the CIGR section 2, Working group no. 14. ADAS Bridgets Dairy Research Centre, Farm Buildings Research Team, Coley park. Read, UK.

CIGR (International Commission of Agricultural and Biosystems Engineering). 2014. The Design of Dairy Cow and Replacement Heifer Housing Report of the CIGR Section II Working Group No. 14, Cattle Housing. CIGR, Gainesville, FL.

de Boyer des Roches, A. 2012. Welfare problems in dairy cows: An epidemiological approach. PhD Thesis. University Blaise PascalClermont-Ferrand II, Clermont-Ferrand, France.

de Boyer des Roches, A., R. Lardy, J. Capdeville, L. Mounier, and I. Veissier. 2019. Do International Commission of Agricultural and Biosystems Engineering (CIGR) dimension recommendations for loose housing of cows improve animal welfare? J. Dairy Sci. 102:10235-10249. https://doi.org/10.3168/jds.2018-16154.

de Boyer des Roches, A., I. Veissier, X. Boivin, E. Gilot-Fromont, and L. Mounier. 2016. A prospective exploration of farm, farmer, and animal characteristics in human-animal relationships: An epidemiological survey. J. Dairy Sci. 99:5573-5585. https://doi.org/10 $.3168 /$ jds.2015-10633.

de Boyer des Roches, A., I. Veissier, M. Coignard, N. Bareille, R. Guatteo, J. Capdeville, E. Gilot-Fromont, and L. Mounier. 2014 The major welfare problems of dairy cows in French commercial farms: An epidemiological approach. Anim. Welf. 23:467-478. https://doi.org/10.7120/09627286.23.4.467.

Dippel, S., M. Dolezal, C. Brenninkmeyer, J. Brinkmann, S. March, U. Knierim, and C. Winckler. 2009a. Risk factors for lameness in cubicle housed Austrian Simmental dairy cows. Prev. Vet. Med. 90:102-112. https://doi.org/10.1016/j.prevetmed.2009.03.014.

Dippel, S., M. Dolezal, C. Brenninkmeyer, J. Brinkmann, S. March, U. Knierim, and C. Winckler. 2009b. Risk factors for lameness in freestall-housed dairy cows across two breeds, farming systems, and countries. J. Dairy Sci. 92:5476-5486. https://doi.org/10 $.3168 /$ jds.2009-2288.

Dohoo, I. R., W. Martin, and H. Stryhn. 2009. Veterinary Epidemiologic Research, second ed. VER Inc, Charlottetown, Canada.

Enea, M. 2017. Speedglm: Fitting Linear and Generalized Linear Models to Large Data Sets. Accessed Nov. 3, 2020. https:/CRAN.R -project.org/package =speedglm.

European Food Safety Authority. 2009. Scientific report on the effects of farming systems on dairy cow welfare and disease. EFSA J. 1143:1-38. https://doi.org/10.2903/j.efsa.2009.1143r.

European Food Safety Authority. 2012. Scientific opinion on the use of animal-based measures to assess welfare of dairy cows. EFSA J. 10:2554. https://doi.org/10.2903/j.efsa.2012.2554.

Fox, J., and G. Monette. 1992. Generalized collinearity diagnostics. J. Am. Stat. Assoc. 87:178-183. https://doi.org/10.1080/01621459 1992.10475190

Fox, J., and S. Weisberg. 2011. An R Companion to Applied Regression. 2nd ed. Sage, Thousand Oaks, CA.

Fregonesi, J. A., and J. D. Leaver. 2002. Influence of space allowance and milk yield level on behaviour, performance and health of dairy cows housed in strawyard and cubicle systems. Livest. Prod. Sci. 78:245-257. https://doi.org/10.1016/S0301-6226(02)00097-0.

Fregonesi, J. A., D. M. Veira, M. A. G. von Keyserlingk, and D. M. Weary. 2007. Effects of bedding quality on lying behavior of dairy cows. J. Dairy Sci. 90:5468-5472. https://doi.org/10.3168/jds.2007 -0494 .

Fregonesi, J. A., M. A. G. von Keyserlingk, C. B. Tucker, D. M. Veira, and D. M. Weary. 2009. Neck-rail position in the free stall affects standing behavior and udder and stall cleanliness. J. Dairy Sci. 92:1979-1985. https://doi.org/10.3168/jds.2008-1604.

Galindo, F., and D. M. Broom. 2000. The relationships between social behaviour of dairy cows and the occurrence of lameness in three herds. Res. Vet. Sci. 69:75-79. https://doi.org/10.1053/rvsc.2000 .0391 .

Gieseke, D., C. Lambertz, and M. Gauly. 2020. Effects of cubicle characteristics on animal welfare indicators in dairy cattle. Animal 1934-1942. https://doi.org/10.1017/S1751731120000609.
Haskell, M. J., L. J. Rennie, V. A. Bowell, M. J. Bell, and A. B. Lawrence. 2006. Housing system, milk production, and zero-grazing effects on lameness and leg injury in dairy cows. J. Dairy Sci. 89:4259-4266. https://doi.org/10.3168/jds.S0022-0302(06)72472 $-9$.

Kielland, C., L. E. Ruud, A. J. Zanella, and O. Østerås. 2009. Prevalence and risk factors for skin lesions on legs of dairy cattle housed in freestalls in Norway. J. Dairy Sci. 92:5487-5496. https://doi .org/10.3168/jds.2009-2293.

Lardy, R., A. de Boyer des Roches, J. Capdeville, R. Bastien, L. Mounier, and I. Veissier. 2020. New recommendations for self-locking barriers to reduce skin injuries in dairy cows. Animal 14:17451756. https://doi.org/10.1017/S175173112000052X.

Lobeck-Luchterhand, K. M., P. R. B. Silva, R. C. Chebel, and M. I. Endres. 2015. Effect of stocking density on social, feeding, and lying behavior of prepartum dairy animals. J. Dairy Sci. 98:240-249. https://doi.org/10.3168/jds.2014-8492.

Meyer, D., A. Zeileis, and K. Hornik. 2017. Vcd: Visualizing Categorical Data. Accessed Nov. 3, 2020. https://cran.r-project.org/web/ packages/vcd/index.html.

Microsoft Corporation, and S. Weston. 2017a. Foreach: Provides Foreach Looping Construct for R. Accessed Nov. 3, 2020. https:// CRAN.R-project.org/package $=$ foreach .

Microsoft Corporation, and S. Weston. 2017b. DoParallel: Foreach Parallel Adaptor for the "parallel" Package. Accessed Nov. 3, 2020. https://CRAN.Rproject.org/package=doParallel.

Nielsen, B. H., P. T. Thomsen, and J. T. Sørensen. 2011. Identifying risk factors for poor hind limb cleanliness in Danish loosehoused dairy cows. Animal 5:1613-1619. https://doi.org/10.1017/ S1751731111000905.

Potterton, S. L., M. J. Green, J. Harris, K. M. Millar, H. R. Whay, and J. N. Huxley. 2011. Risk factors associated with hair loss, ulceration, and swelling at the hock in freestall-housed UK dairy herds. J. Dairy Sci. 94:2952-2963. https://doi.org/10.3168/jds .2010-4084.

Prunier, A., L. Mounier, P. Le Neindre, C. Leterrier, P. Mormede, V. Paulmier, P. Prunet, C. Terlouw, and R. Guatteo. 2013. Identifying and monitoring pain in farm animals: A review. Animal 7:998-1010. https://doi.org/10.1017/S1751731112002406.

R Core Team. 2018. R: A Language and Environment for Statistical Computing. R Foundation for Statistical Computing, Vienna Austria.

Refaeilzadeh, P., L. Tang, and H. Liu. 2016. Cross-Validation. L. Liu and M.T. Özsu, ed. Springer, New York, NY.

Reneau, J. K., A. J. Seykora, B. J. Heins, M. I. Endres, R. J. Farnsworth, and R. F. Bey. 2005. Association between hygiene scores and somatic cell scores in dairy cattle. J. Am. Vet. Med. Assoc. 227:1297-1301. https://doi.org/10.2460/javma.2005.227.1297.

Ruud, L. E., and K. E. Bøe. 2011. Flexible and fixed partitions in freestalls -Effects on lying behavior and cow preference. J. Dairy Sci. 94:4856-4862. https://doi.org/10.3168/jds.2010-3824.

Schreiner, D. A., and P. L. Ruegg. 2003. Relationship between udder and leg hygiene scores and subclinical mastitis. J. Dairy Sci. 86:3460-3465. https://doi.org/10.3168/jds.S0022-0302(03)73950 -2 .

Sing, T., O. Sander, N. Beerenwinkel, and T. Lengauer. 2005. ROCR: Visualizing classifier performance in R. Bioinformatics 21:39403941. https://doi.org/10.1093/bioinformatics/bti623.

Sogstad, A. M., T. Fjeldaas, and O. Østerås. 2005. Lameness and claw lesions of the Norwegian Red dairy cattle housed in free stalls in relation to environment, parity and stage of lactation. Acta Vet. Scand. 46:203-217. https://doi.org/10.1186/1751-0147-46-203.

Toma, B., B. Dufour, J.-J. Benet, J. Rivière, A. Shaw, F. Moutou, and Association pour l'étude de l'épidémiologie des maladies animales. 2018. Épidémiologie appliquée à la lutte collective contre les maladies animales transmissibles majeures. AEEMA, Maisons-Alfort, France.

Tucker, C. B., D. M. Weary, and D. Fraser. 2005. Influence of neckrail placement on free-stall preference, use, and cleanliness. J. Dairy Sci. 88:2730-2737. https://doi.org/10.3168/jds.S0022 $-0302(05) 72952-0$ 
Veissier, I., J. Capdeville, and E. Delval. 2004. Cubicle housing systems for cattle: Comfort of dairy cows depends on cubicle adjustment. J. Anim. Sci. 82:3321-3337. https://doi.org/10.2527/2004 $82113321 \mathrm{x}$

Venables, W. N., and B. D. Ripley. 2002. Modern Applied Statistics with S. 4th ed. Springer, New York, NY.

Weary, D. M., and I. Taszkun. 2000. Hock lesions and free-stall design. J. Dairy Sci. 83:697-702. https://doi.org/10.3168/jds.S0022 -0302(00)74931-9.

Welfare Quality. 2009. Welfare Quality Assessment protocol for cattle. Welfare Quality Consortium, Lelystad, the Netherlands.

Westin, R., A. Vaughan, A. M. de Passillé, T. J. DeVries, E. A. Pajor, D. Pellerin, J. M. Siegford, E. Vasseur, and J. Rushen. 2016a. Lying times of lactating cows on dairy farms with automatic milking systems and the relation to lameness, leg lesions, and body condition score. J. Dairy Sci. 99:551-561. https://doi.org/10.3168/jds $.2015-9737$

Westin, R., A. Vaughan, A. M. de Passillé, T. J. DeVries, E. A. Pajor, D. Pellerin, J. M. Siegford, A. Witaifi, E. Vasseur, and J. Rush- en. 2016b. Cow- and farm-level risk factors for lameness on dairy farms with automated milking systems. J. Dairy Sci. 99:3732-3743. https://doi.org/10.3168/jds.2015-10414.

Zaffino Heyerhoff, J. C., S. J. LeBlanc, T. J. DeVries, C. G. R. Nash, J. Gibbons, K. Orsel, H. W. Barkema, L. Solano, J. Rushen, A. M. de Passillé, and D. B. Haley. 2014. Prevalence of and factors associated with hock, knee, and neck injuries on dairy cows in freestall housing in Canada. J. Dairy Sci. 97:173-184. https://doi .org/10.3168/jds.2012-6367.

\section{ORCIDS}

Romain Lardy ๑ https://orcid.org/0000-0003-1338-8553

Alice de Boyer des Roches ( https://orcid.org/0000-0002-6903-7456

Jacques Capdeville @ https://orcid.org/0000-0002-5391-9083

Isabelle Veissier ๑ https://orcid.org/0000-0002-8497-5395 